\section{A hydrated crystalline calcium carbonate phase: Calcium carbonate hemihydrate}

\author{
Zhaoyong Zou' ${ }^{*}$, Wouter J. E. M. Habraken', Galina Matveeva ${ }^{2}$, Anders C. S. Jensen ${ }^{1}$, \\ Luca Bertinetti', Matthew A. Hood ${ }^{1}$, Chang-yu Sun ${ }^{3}$, Pupa U. P. A. Gilbert ${ }^{3,4}$, \\ Iryna Polishchuk ${ }^{5}$, Boaz Pokroy ${ }^{5}$, Julia Mahamid ${ }^{6,7}$, Yael Politi' ${ }^{1}$, Steve Weiner ${ }^{8}$, \\ Peter Werner ${ }^{9}$, Sebastian Bette ${ }^{10}$, Robert Dinnebier ${ }^{10}$, Ute Kolb ${ }^{2,11}$, \\ Emil Zolotoyabko ${ }^{5}$, Peter Fratzl ${ }^{1} \dagger$
}

As one of the most abundant materials in the world, calcium carbonate, $\mathrm{CaCO}_{3}$, is the main constituent of the skeletons and shells of various marine organisms. It is used in the cement industry and plays a crucial role in the global carbon cycle and formation of sedimentary rocks. For more than a century, only three polymorphs of pure $\mathrm{CaCO}_{3}-$ calcite, aragonite, and vaterite-were known to exist at ambient conditions, as well as two hydrated crystal phases, monohydrocalcite $\left(\mathrm{CaCO}_{3} \cdot 1 \mathrm{H}_{2} \mathrm{O}\right)$ and ikaite $\left(\mathrm{CaCO}_{3} \cdot 6 \mathrm{H}_{2} \mathrm{O}\right)$. While investigating the role of magnesium ions in crystallization pathways of amorphous calcium carbonate, we unexpectedly discovered an unknown crystalline phase, hemihydrate $\mathrm{CaCO}_{3} \cdot 1 / 2 \mathrm{H}_{2} \mathrm{O}$, with monoclinic structure. This discovery may have important implications in biomineralization, geology, and industrial processes based on hydration of $\mathrm{CaCO}_{3}$.

C alcium carbonate $\left(\mathrm{CaCO}_{3}\right)$ makes up nearly $4 \%$ of Earth's crust and is produced mainly by the sedimentation of skeletal remains of marine organisms accumulated over millions of years in the form of, for example, chalk and limestone. Calcium carbonate minerals are involved in the global carbon cycle and have been intensively investigated because of their importance for paleoclimate reconstructions (1), ocean acidification (2-4), and biomineralization $(5,6)$. Calcium carbonate is often referenced as a model system for studying nucleation and crystallization mechanisms from ion solutions $(7,8)$. For more than a century, three anhydrous crystalline polymorphs of $\mathrm{CaCO}_{3}$ were known to exist at ambient conditionscalcite, aragonite, and vaterite-as well as two hydrated crystalline phases, monohydrocalcite $(\mathrm{MHC})\left(\mathrm{CaCO}_{3} \cdot 1 \mathrm{H}_{2} \mathrm{O}\right)$ and ikaite $\left(\mathrm{CaCO}_{3} \cdot 6 \mathrm{H}_{2} \mathrm{O}\right)$

\footnotetext{
${ }^{1}$ Department of Biomaterials, Max Planck Institute of Colloids and Interfaces, Potsdam, Germany. ${ }^{2}$ Johannes GutenbergUniversität Mainz, Institut für Anorganische und Analytische Chemie, Mainz, Germany. ${ }^{3}$ Department of Physics, University of Wisconsin-Madison, Madison, WI, USA. ${ }^{4}$ Departments of Chemistry, Geoscience, and Materials Science, University of Wisconsin-Madison, Madison, WI, USA. ${ }^{5}$ Department of Materials Science and Engineering, Technion-Israel Institute of Technology, Haifa, Israel. ${ }^{6}$ Department of Molecular Structural Biology, Max Planck Institute of Biochemistry, Martinsried, Germany. ${ }^{7}$ Structural and Computational Biology Unit, European Molecular Biology Laboratory, Heidelberg, Germany. ${ }^{8}$ Department of Structural Biology, Weizmann Institute of Science, Rehovot, Israel. ${ }^{9}$ Max Planck Institute of Microstructure Physics, Halle, Germany. ${ }^{10}$ Max Planck Institute for Solid State Research, Stuttgart, Germany. ${ }^{11}$ Institute of Applied Geosciences, TU Darmstadt, Darmstadt, Germany.

*Present address: State Key Laboratory of Advanced Technology for Materials Synthesis and Processing, Wuhan University of Technology, Wuhan, China.

†Corresponding author. Email: fratzl@mpikg.mpg.de
}

(9). In addition to these crystalline phases, calcium carbonate also exists in various amorphous states, known as amorphous calcium carbonate (ACC), which, together with organic macromolecules and inorganic ions, play a crucial role in controlling the formation of crystalline calcium carbonate biominerals (10-13). Here, we report the discovery and comprehensive characterization of a hitherto unknown hydrated crystalline calcium carbonate compound with a composition of $\mathrm{CaCO}_{3} \cdot 1 / 2 \mathrm{H}_{2} \mathrm{O}$, i.e., calcium carbonate hemihydrate (CCHH). This phase forms from ACC in solution in the presence of $\mathrm{Mg}^{2+}$ ions with a $\mathrm{Mg} / \mathrm{Ca}$ molar ratio of $\sim 5 / 1$. At the same time, the $\mathrm{Mg}$ concentration in $\mathrm{CCHH}$ crystallites stays below 2 atomic \%. Compared with the same process for calcite, entering of $\mathrm{Mg}^{2+}$ ions into $\mathrm{CCHH}$ is hampered because of the differences in the cation coordination (14). As we show below, $\mathrm{Ca}$ is eightfold coordinated in $\mathrm{CCHH}$ but sixfold coordinated in calcite. It is proposed that $\mathrm{Mg}^{2+}$ ions in solution inhibit the dehydration of ACC and control the hydration level of the crystalline phases. The discovery of this hydrated crystalline calcium carbonate phase emphasizes the importance of amorphous precursors and $\mathrm{Mg}^{2+}$ in controlling the crystallization pathways of calcium carbonate.

We synthesized CCHH by adding a premixed solution of $\mathrm{CaCl}_{2}$ and $\mathrm{MgCl}_{2}$ to $\mathrm{Na}_{2} \mathrm{CO}_{3}$ solution (15). ACC precipitates immediately, whereas $\mathrm{CCHH}$ starts to form after $2000 \mathrm{~s}$. The $\mathrm{CCHH}$ formation is completed in nearly $4200 \mathrm{~s}$. We first determined the composition of CCHH by combining inductively coupled plasma optical emission spectrometry (ICP-OES) (table S1) and thermogravimetric analysis/differential scanning calorimetry (TGA/DSC) analysis (fig. S1), giving the preliminary chemical formula of $\mathrm{Ca}_{0.98} \mathrm{Mg}_{0.02} \mathrm{CO}_{3} \cdot m \mathrm{H}_{2} \mathrm{O}$ with factor $m=0.48$. Factor $m \approx 0.5$ was obtained by removing the amount of physisorbed water (evaporated below $115^{\circ} \mathrm{C}$ ) (fig. S1) from the total water loss measured by TGA.

Morphological analysis shows that $\mathrm{CCHH}$ appears as needlelike crystals with a diameter of $\sim 200 \mathrm{~nm}$ and a length between 1 and $5 \mu \mathrm{m}$ (Fig. 1A), which are further composed of wellaligned nanocrystals with a diameter of $\sim 30 \mathrm{~nm}$ (Fig. 1B). The infrared (IR) and Raman spectra of CCHH (Fig. 1, C and D) differ substantially from the spectra of all known calcium carbonate phases. However, the spectral peaks we observed can be attributed to known vibrational modes for calcium carbonate-based structures (table S2) (16). The most prominent feature is the symmetric stretching mode, $v_{1}$, of the carbonate group $\left(\mathrm{CO}_{3}\right)$, which appears as a single sharp peak at $1102 \mathrm{~cm}^{-1}$ (full width at half maximum: $4 \mathrm{~cm}^{-1}$ ) in the Raman spectrum and a weak band at $1096 \mathrm{~cm}^{-1}$ in the IR spectrum. These wave numbers are substantially higher than those known for all other calcium carbonate phases; for example, in calcite, $v_{1}=1085 \mathrm{~cm}^{-1}$ (17).

In addition, the single sharp peak without splitting suggests a solitary site symmetry of the carbonate within the structure (18). The asymmetric stretching mode, $v_{3}$, in the IR spectrum splits into four peaks, suggesting that the carbonate groups in the CCHH crystal structure are somewhat distorted. Without any distortions, the $v_{3}$ vibrational mode is only allowed to be doubly degenerated. Similar carbonate vibrational modes exist in huntite $\left[\mathrm{Mg}_{3} \mathrm{Ca}\left(\mathrm{CO}_{3}\right)_{4}\right]$, barytocalcite $\left[\mathrm{BaCa}\left(\mathrm{CO}_{3}\right)_{2}\right]$, and shortite $\left[\mathrm{Na}_{2} \mathrm{Ca}_{2}\left(\mathrm{CO}_{3}\right)_{3}\right]$ $(19,20)$. The in-plane bending mode, $v_{4}$, splits into two peaks at 700 and $731 \mathrm{~cm}^{-1}$ in the Raman spectrum and appears as weak peaks at 692 and $723 \mathrm{~cm}^{-1}$ in the IR spectrum, which also differs from the bending mode appearance in other calcium carbonate phases.

For structural analysis, we carried out highresolution x-ray powder diffraction (HRXRPD) measurements at the dedicated beamline ID22 of the European Synchrotron Radiation Facility. Even a quick analysis of the collected diffraction pattern (Fig. 1E) allows us to conclude that it does not fit any known calcium carbonate phases. Unidentified diffraction peaks of highest intensity appear at Bragg spacings $(d)$ of $5.31 \AA(2 \theta=$ $\left.5.36^{\circ}\right), 5.22 \AA\left(2 \theta=5.45^{\circ}\right), 3.03 \AA\left(2 \theta=9.39^{\circ}\right)$, and $2.50 \AA\left(2 \theta=11.37^{\circ}\right)$. Detailed analysis of powder diffraction data, based on the developed structural solution, is given below and strongly supports the appearance of the previously unknown phase. In addition, the extracted pair distribution function pattern (fig. S2A) and x-ray absorption near-edge structure (XANES) spectra collected at the Ca K-edge (fig. S2B) of $\mathrm{CCHH}$ show some similarities to those of ACC and MHC but are distinct from those known for anhydrous crystalline phases of $\mathrm{CaCO}_{3}$. XANES spectra, taken at the O K-edge (fig. S2C) and Ca L-edge (fig. S2D) by using photoemission electron microscopy (PEEM), differ from those collected from anhydrous calcium carbonate phases or any other $\mathrm{CaCO}_{3}$ phases. 
We monitored the time-dependent $\mathrm{pH}$ and $\mathrm{Ca}^{2+}$ activity in solution (Fig. 2, A and B) to determine the range of reaction parameters for $\mathrm{CCHH}$ formation and correlated them with the products formed at different time points (Fig. 2, C to F). We subdivided the reaction kinetics into three stages. At stage I, ACC with $\sim 6.5 \mathrm{~mol} \%$ of $\mathrm{Mg}$ is precipitated immediately and remains stable in the mother solution for $\sim 20 \mathrm{~min}$. According to our TGA data, it comprises nearly one molecule of water per one molecule of $\mathrm{CaCO}_{3}$. At stage II, this monohydrated amorphous phase transforms into $\mathrm{CCHH}$, as indicated by a sharp decrease in the $\mathrm{Ca}^{2+}$ activity. Here, the $\mathrm{Mg}$ content in $\mathrm{CCHH}$ decreases to $\sim 1.5 \mathrm{~mol} \%$, which, together with an abnormal increase in $\mathrm{pH}$, suggests that at this point $\mathrm{Mg}$ ions are released back into solution owing to dissolution of magnesium carbonate molecules stored in ACC. At stage III, CCHH gradually transforms into MHC, which is manifested by a slow decrease in $\mathrm{pH}$ and $\mathrm{Ca}^{2+}$ activity lasting nearly 11 hours. The transformation between the three stages also includes release and reacquisition of water molecules. ACC and MHC are monohydrated, whereas $\mathrm{CCHH}$ contains roughly half the amount of water. The structural aspects of the time-dependent transformations were also tracked by laboratory $\mathrm{x}$-ray powder diffraction (XRPD) measurements (Fig. 2D).
The Raman spectra (Fig. 2E) help us easily distinguish $\mathrm{ACC}, \mathrm{CCHH}$, and $\mathrm{MHC}$ by comparing the wave numbers of the $v_{1}$-mode positioned, respectively, at 1083, 1102, and $1069 \mathrm{~cm}^{-1}$. In IR spectra (Fig. 2F), we recognized the characteristic splitting of the $v_{3}$ mode for ACC, which elaborates into four peaks for $\mathrm{CCHH}$ and turns back to two peaks for MHC. We used scanning electron microscopy (SEM) images (fig. S3) to show that the initially precipitated ACC nanoparticles are attached to the needlelike $\mathrm{CCHH}$ crystals during the ACC-to-CCHH transformation and, subsequently, $\mathrm{CCHH}$ needles are attached to the surface of MHC crystals. We concluded that CCHH is thermodynamically a metastable phase formed from an amorphous precursor. We stress that, in solution, it gradually transforms into MHC, but is stable (at least for a few months) when stored in vacuum. Transformation of the needleshaped CCHH crystals to MHC resembles that of needle-shaped hemihydrate bassanite crystals $\left(\mathrm{CaSO}_{4} \cdot 1 / 2 \mathrm{H}_{2} \mathrm{O}\right)$ to gypsum $\left(\mathrm{CaSO}_{4} \cdot 2 \mathrm{H}_{2} \mathrm{O}\right)(21)$.

We performed experiments at different initial carbonate concentrations and $\mathrm{Mg}^{2+}$ contents to uncover optimal conditions for $\mathrm{CCHH}$ synthesis (figs. S4 to S6). We found that $\mathrm{CCHH}$ can only be synthesized in solutions containing intermediate concentrations of $\mathrm{Mg}^{2+}$ and carbonate (Fig. 3A). In addition, the $\mathrm{Mg}^{2+}$ content in the ACC must be maintained between 5 and $9 \%$. A substantially lower $\mathrm{Mg}^{2+}$ content in the $\mathrm{ACC}$ as compared with the initial $\mathrm{Mg}^{2+}$ content in solution also suggests that after ACC formation the solution is enriched in $\mathrm{Mg}^{2+}$. Therefore, knowing the $\mathrm{Mg}^{2+} / \mathrm{Ca}^{2+}$ molar ratio in solution after ACC formation is important (Fig. 3B). For $\mathrm{CCHH}$ formation, this ratio is between 4.3 and 6.1 (i.e., $~ 5.2$ ), which is characteristic for modern seawater. We assume that the dissolved $\mathrm{Mg}^{2+}$ inhibits the crystallization of calcite in our system and promotes the formation of CCHH. We validated our hypothesis with additional experiments, in which $\mathrm{Mg}^{2+}$ ions were added after precipitation of pure ACC (fig. S7). $\mathrm{CCHH}$ is also formed in this scenario, but only if the molar ratio of $\mathrm{Mg}^{2+} / \mathrm{Ca}^{2+}$ in solution is in the range of $\sim 4$ to 6 (table S3).

To determine the atomic structure of $\mathrm{CCHH}$, we resorted to automated electron diffraction tomography (ADT) (22) and HRXRPD (Fig. 1E), as the crystals were too small for single-crystal $\mathrm{XRD}$ and not stable under the electron beam used in transmission electron microscopy (TEM). The HRXRPD pattern has both broad and sharp reflections, with some peaks having a characteristic triangular shape that indicates strong stacking-fault-like structural disorder $(23,24)$. Because ab initio crystal structure solution based
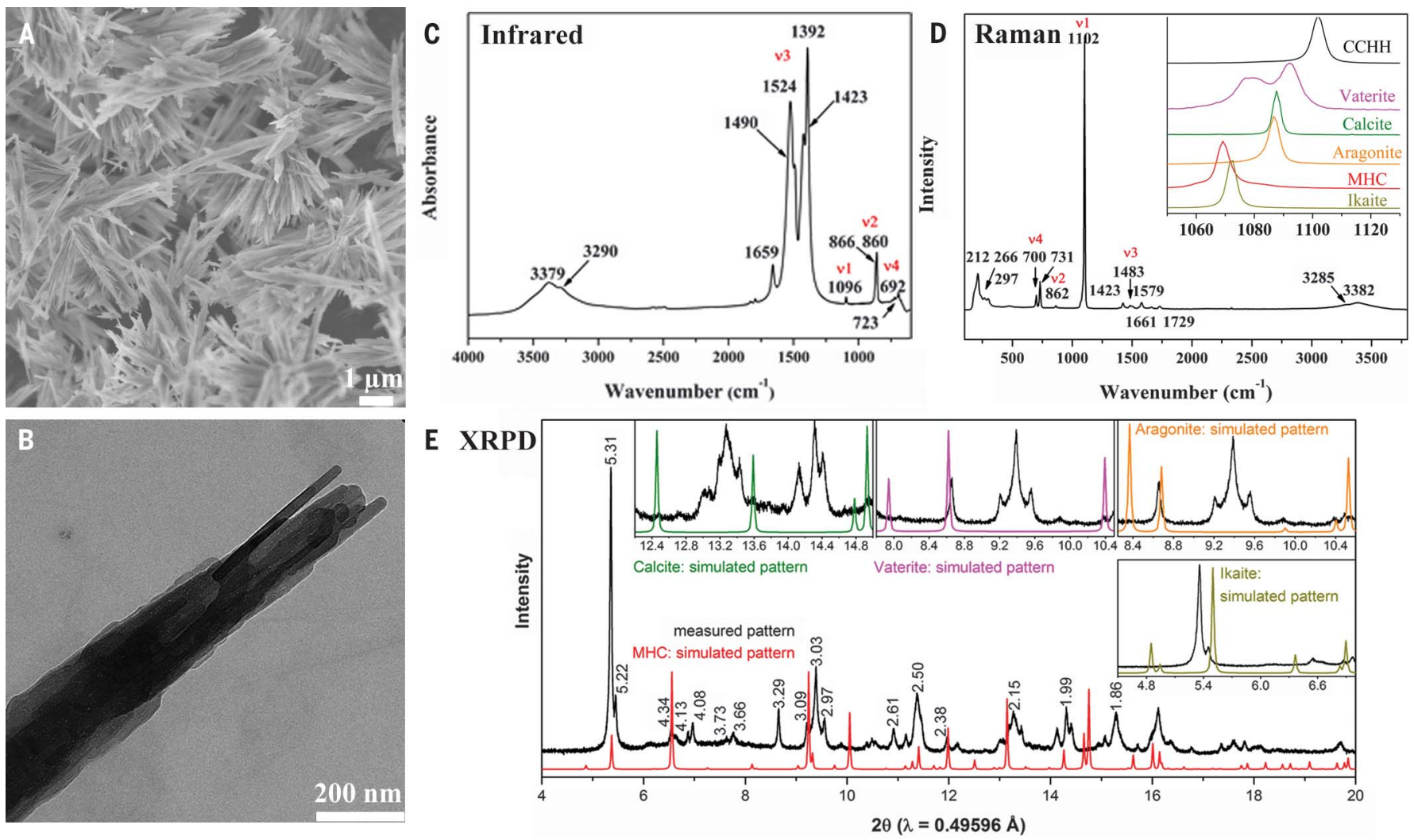

Fig. 1. Morphological and structural characterization of $\mathrm{CCHH}$. SEM (A) and TEM (B) images, IR (C) and Raman (D) spectra, and synchrotron HRXRPD pattern (E) of CCHH using a wavelength of $0.49596 \AA$. The inset in (D) shows a comparison of the Raman spectra of $\mathrm{CCHH}$ with those of other calcium carbonate phases in the range of 1050 to $1115 \mathrm{~cm}^{-1}$. The insets in (E) show comparisons of the measured HRXRPD pattern of $\mathrm{CCHH}$ with simulated patterns of other calcium carbonate phases. 

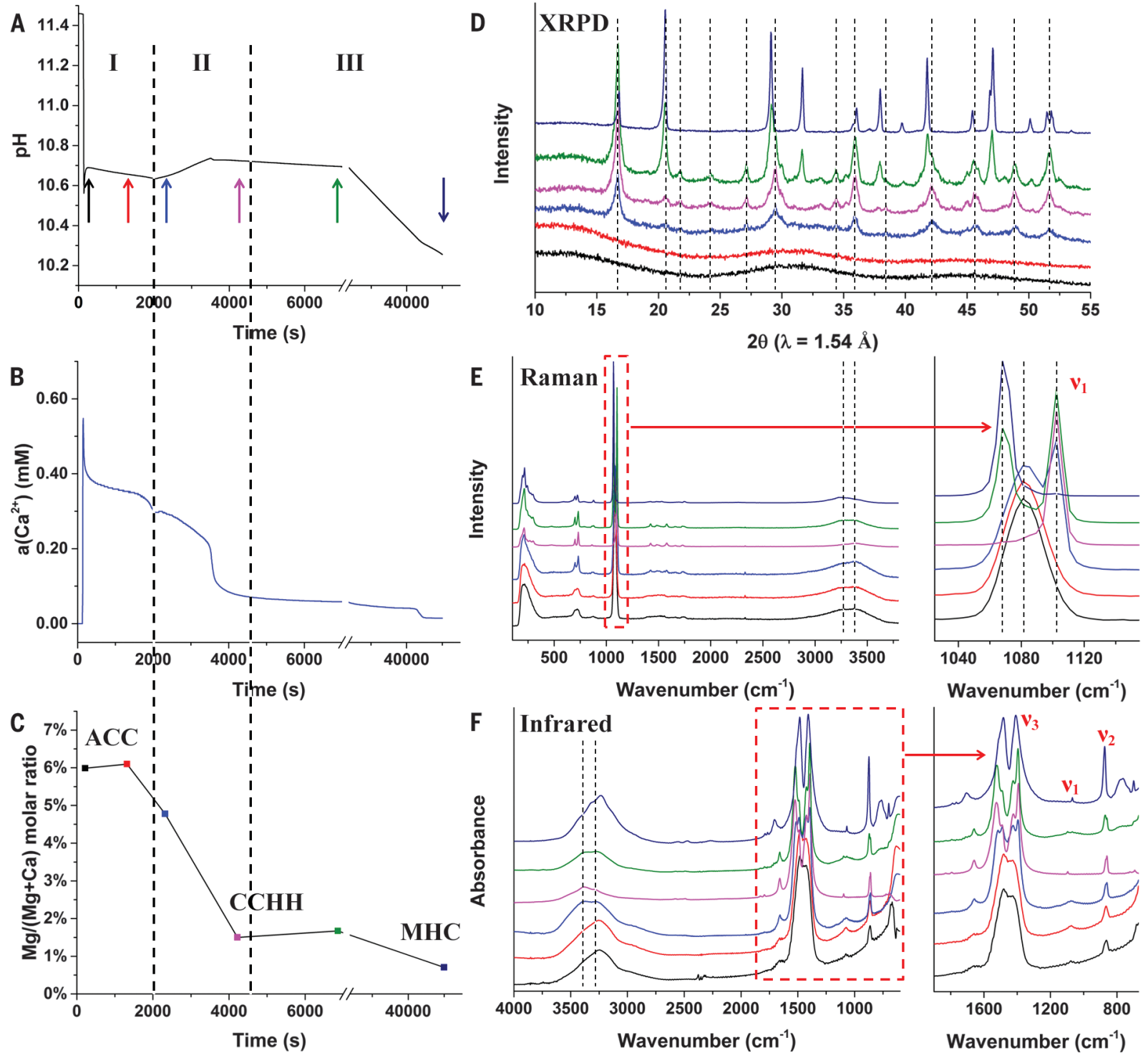

Fig. 2. Chemical and structural evolution during the formation and transformation of $\mathbf{C C H H}$ in solution. $\mathrm{pH}(\mathbf{A})$ and $\mathrm{Ca}^{2+}$ activity

(B) changes in the reaction solution at a calcium carbonate concentration of $40 \mathrm{mM}$ in the presence of $20 \% \mathrm{Mg}$. The $\mathrm{Mg} /(\mathrm{Mg}+\mathrm{Ca})$ molar ratio (C),

laboratory XRPD pattern (D), and Raman (E) and IR (F) spectra of the samples extracted at several time points, marked by the differently colored arrows in (A). Dashed lines in (D) to (F) help with visualization of the difference in the peak positions. $\lambda$ indicates $x$-ray wavelength. on HRXRPD data was not possible, we applied the ADT method that allows for structural analysis of single nanocrystals. Our three-dimensional reconstruction of $\mathrm{ADT}$ data taken from needleshaped crystals (fig. S8) led to a monoclinic unit cell for $\mathrm{CaCO}_{3} \cdot 1 / 2 \mathrm{H}_{2} \mathrm{O}$ with space group $P 2_{1} / c$ and lattice parameters $a=9.33 \AA, b=10.44 \AA$, $c=6.16 \AA, \alpha=90^{\circ}, \beta=90.5^{\circ}$, and $\gamma=90^{\circ}$ (table S4). The structure solution with a final residual $\mathrm{R}(\mathrm{F})$ of 0.219 (table S5), implemented using the direct method approach, yielded atomic positions of calcium and carbonate in a rational geometry, as well as the positions of the additional oxygen from water molecules (fig. S9 and data S1). The simulated HRXRPD pattern for this structure, in general, fits reasonably well the measured synchrotron diffraction pattern (fig. S10), though some extra reflections still exist, which we attributed to a small amount of additional phases, structurally interrelated with CCHH. This situation in some ways resembles that of vaterite $(25,26)$.

Because of the slow transformation of $\mathrm{CCHH}$ into MHC in solution (Fig. 2), the presence of the latter phase is reasonable and we clearly see the 111 reflection of $\mathrm{MHC}$ at $2 \theta=6.55^{\circ}$ in the HRXRPD pattern (fig. S10). In addition, we found another solid phase, exhibiting a platelike morphology (fig. S8) by ADT analysis. On the basis of the unit cell dimensions (table S4), this phase most likely is another calcium carbonate hydrate $\mathrm{CaCO}_{3} \cdot n \mathrm{H}_{2} \mathrm{O}$ with $n=3 / 4$.

Therefore, the most probable origin of the structural disorder in $\mathrm{CCHH}$ samples is incorporation of additional water molecules into the crystal structure of CCHH. This leads to coexist- ing coherent domains of $\mathrm{CCHH}, \mathrm{CaCO}_{3} \cdot 3 / 4 \mathrm{H}_{2} \mathrm{O}$, and $\mathrm{MHC}$ within the crystals. The borders between domains appear as stacking faults. Such an intergrowth is likely only when the defects are commensurate. To confirm this, we transformed the unit cells of $\mathrm{CaCO}_{3} \cdot 3 / 4 \mathrm{H}_{2} \mathrm{O}$ and $\mathrm{MHC}$ into the metric of the cell of CCHH (table S4). After the transformation, we found only small mismatches ( $2 \%)$ for the transformed $a$ and $b$ lattice parameters, whereas the $c$ lattice parameter of MHC has a large mismatch of $22.56 \%$, with respect to the $\mathrm{CCHH}$ lattice. Therefore, commensurate crystallographic intergrowth is possible only in the $c$ direction of CCHH.

A comparison of the layered motifs in the crystal structures of $\mathrm{CCHH}$ and MHC perpendicular to the $c$ axis (Fig. 4) shows that the packing in $\mathrm{MHC}$ is denser than in $\mathrm{CCHH}$ (see 

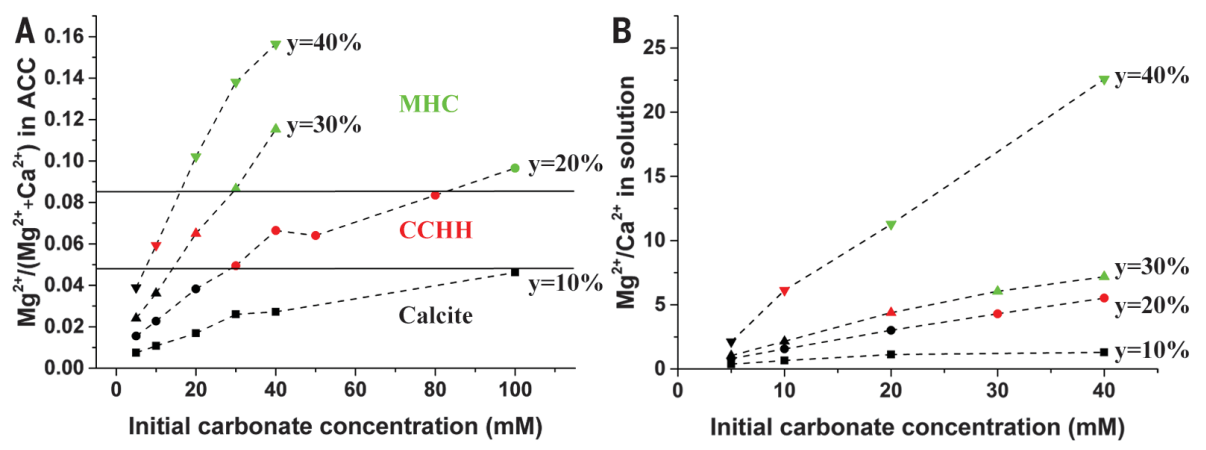

Fig. 3. Diagram for $\mathbf{C C H H}$ formation under various conditions. (A) The $\mathrm{Mg}^{2+} /\left(\mathrm{Mg}^{2+}+\mathrm{Ca}^{2+}\right)$ molar ratio in ACC, as a function of the initial carbonate concentration in solution ( 5 to $100 \mathrm{mM}$ ) and initial $\mathrm{Mg}^{2+}$ content $\left[y=\mathrm{Mg}^{2+} /\left(\mathrm{Mg}^{2+}+\mathrm{Ca}^{2+}\right)\right.$ molar ratio] in solution upon mixing (10 to $40 \%$ ). (B) The $\mathrm{Mg}^{2+} / \mathrm{Ca}^{2+}$ molar ratio in solution after ACC formation was estimated on the basis of $\mathrm{Ca}^{2+}$ activity of the solution and the $\mathrm{Mg}^{2+} /\left(\mathrm{Mg}^{2+}+\mathrm{Ca}^{2+}\right)$ ratio in the ACC. Differently colored points are associated with different crystalline phases (black, red, and green represent, respectively, calcite, $\mathrm{CCHH}$, and $\mathrm{MHC}$ ). The horizontal lines separate the diagram regions in which the three distinct mineral phases form.

Fig. 4. Comparison of layered motifs in the crystal structures of CCHH and MHC. (A and C) $\mathrm{CCHH}\left(\mathrm{CaCO}_{3} \cdot 1 / 2 \mathrm{H}_{2} \mathrm{O}\right)$ and (B and $\mathbf{D}) \mathrm{MHC}$ $\left(\mathrm{CaCO}_{3} \cdot 1 \mathrm{H}_{2} \mathrm{O}\right)$. The layers of $\mathrm{CCHH}$ consist of $\mathrm{Ca}\left(\mu_{2}-\mathrm{CO}_{3}\right)_{2 / 5}\left(\mu_{1}-\mathrm{CO}_{3}\right)_{3 / 5}$ $\left(\mathrm{H}_{2} \mathrm{O}\right)_{1 / 2}$ double zigzag chains running along the a axis $(A)$; here, differently oriented (up and down) carbonate groups are indicated by indices $\mu_{2}$ and $\mu_{1}$. Stacking in the $c$ direction occurs in a conventional $A B A B$ fashion (C) with an interlayer spacing (the distance between $\mathrm{Ca}$ planes) equal to $3.08 \AA$. The layers of MHC consist of a dense packing of $\mathrm{Ca}\left(\mu_{2}-\mathrm{CO}_{3}\right)_{2 / 4}\left(\mu_{1}-\mathrm{CO}_{3}\right)_{2 / 4}$ $\left(\mathrm{H}_{2} \mathrm{O}\right)_{2 / 2}$ polyhedra (B)
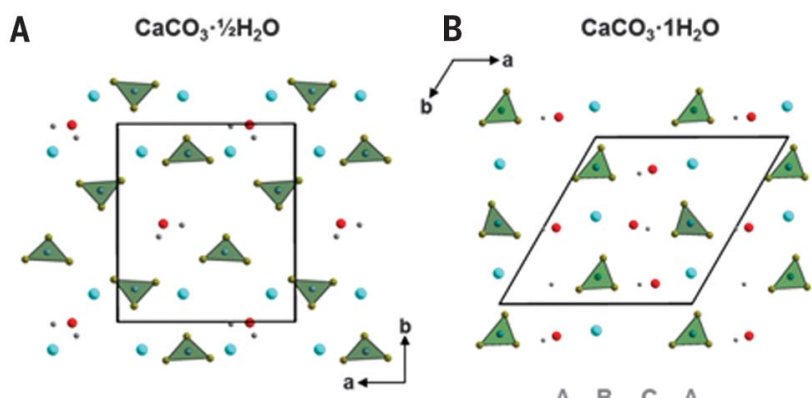

c
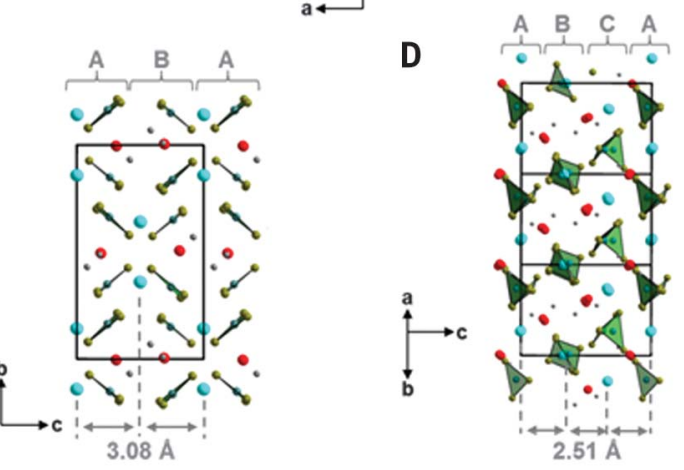

Along the $c$ axis, condensed layers are stacked in an ABC fashion (D) with an interlayer distance of $2.51 \AA$. Different types of atoms are colored as follows: Ca, blue; carbonate groups, green; oxygen from water, red; and hydrogen, gray.

also table S4). Hence, the structural transition from $\mathrm{CCHH}$ to $\mathrm{MHC}$ does not occur by an intercalation of additional water molecules with shifts in the stacking order of the layers, but instead the transition causes a comprehensive change in the layers' constitution and stacking. An example of this effect is on the 002 reflection of CCHH $\left(d=3.08 \AA, 2 \theta=9.23^{\circ}\right)$, which has a very pronounced triangular shape broadening toward lower $d$ spacing (fig. S11).

To check the suitability of the considered microstructure model that contains a commensurate crystallographic intergrowth, we performed a Pawley fit (27) using three phases with transformed unit cells (table S4). This allowed us to successfully index and reproduce all reflections in the HRXRPD pattern (fig. S12). In particular, we can describe the sharp reflections at $2 \theta=6.5^{\circ}$ $(d=4.37 \AA)$ and at $2 \theta=8.7^{\circ}(d=3.27 \AA)$ using the transformed cells of $\mathrm{MHC}$ and $\mathrm{CaCO}_{3} \cdot 3 / 4 \mathrm{H}_{2} \mathrm{O}$. Secondly, the preferred model provided an excellent fit (with a weighted profile R-factor of 7.55\%) to the measured synchrotron HRXRPD pattern (fig. S12), allowing us to refine the lattice parameters (table S6). Moreover, the model also fits the spectroscopy data, indicating that inhomogeneous distortion of the carbonate groups is caused by the abovementioned structural disorder.

Final proof of the microstructure model would require complex DIFFaX (28) simulations, including three stacking regimes with different layer constitutions, transitions among them, and specific faults within each individual regime; the structural characterization of $\mathrm{CaCO}_{3} \cdot 3 / 4 \mathrm{H}_{2} \mathrm{O}$; and a global optimization of the measured pattern by a Rietveld-compatible approach. Because the routines (29), which were successfully applied to faulted samples, were developed for less complex faulting models $(24,30)$, this is not currently possible. Besides, the addition of $\mathrm{CaCO}_{3} \cdot 3 / 4 \mathrm{H}_{2} \mathrm{O}$ and $\mathrm{MHC}$ phases is very minor. Because the water content, according to our TGA, is close to $1 / 2 \mathrm{H}_{2} \mathrm{O}$ per $\mathrm{CaCO}_{3}$, we estimate that these phases comprise not more than a few percent. In fact, Rietveld refinement with $\mathrm{CCHH}$ and $\mathrm{MHC}$ yields less than $4 \%$ for the latter. Therefore, more than $90 \%$ in the reaction products is the $\mathrm{CCHH}$ phase.

The discovery of $\mathrm{CCHH}$, its formation pathways, and its complete structure determination (data S1) substantially expand our knowledge of the $\mathrm{CaCO}_{3}$ family. An essential step forward would be the search for CCHH crystals, via their diffraction and spectroscopic fingerprints, in nature (rocks, biomineralization outcomes) and within the products of relevant technological processes.

\section{REFERENCES AND NOTES}

1. J. W. Beck et al., Science 257, 644-647 (1992)

2. F. J. Millero, Chem. Rev. 107, 308-341 (2007).

3. M. Cusack, A. Freer, Chem. Rev. 108, 4433-4454 (2008).

4. S. Goffredo et al., Nat. Clim. Chang. 4, 593-597 (2014).

5. L. B. Gower, Chem. Rev. 108, 4551-4627 (2008).

6. L. J. de Nooijer, H. J. Spero, J. Erez, J. Bijma, G. J. Reichart, Earth Sci. Rev. 135, 48-58 (2014).

7. D. Gebauer, A. Völkel, H. Cölfen, Science 322, 1819-1822 (2008).

8. M. H. Nielsen, S. Aloni, J. J. De Yoreo, Science 345, 1158-1162 (2014)

9. J. W. Morse, R. S. Arvidson, A. Lüttge, Chem. Rev. 107 342-381 (2007).

10. Y. Politi, T. Arad, E. Klein, S. Weiner, L. Addadi, Science 306 , 1161-1164 (2004).

11. L. Addadi, S. Raz, S. Weiner, Adv. Mater. 15, 959-970 (2003).

12. L. Addadi, D. Joester, F. Nudelman, S. Weiner, Chemistry 12 980-987 (2006).

13. Y. U. T. Gong et al., Proc. Natl. Acad. Sci. U.S.A. 109 6088-6093 (2012).

14. W. Sun, S. Jayaraman, W. Chen, K. A. Persson, G. Ceder, Proc. Natl. Acad. Sci. U.S.A. 112, 3199-3204 (2015)

15. Z. Zou et al., Chem. Mater. 27, 4237-4246 (2015).

16. F. A. Andersen et al., Acta Chem. Scand. 45, 1018-1024 (1991).

17. W. D. Bischoff, S. K. Sharma, F. T. Mackenzie, Am. Mineral. 70 581-589 (1985)

18. G. Behrens, L. T. Kuhn, R. Ubic, A. H. Heuer, Spectrosc. Lett. 28, 983-995 (1995)

19. H. H. Adler, P. F. Kerr, Am. Mineral. 48, 839-853 (1963).

20. R. L. Frost, M. J. Dickfos, Spectrochim. Acta A 71, 143-146 (2008)

21. A. E. S. Van Driessche et al., Science 336, 69-72 (2012).

22. U. Kolb, E. Mugnaioli, T. E. Gorelik, Cryst. Res. Technol. 46, 542-554 (2011).

23. B. E. Warren, Phys. Rev. 59, 693-698 (1941)

24. S. Bette et al., Dalton Trans. 46, 15216-15227 (2017).

25. L. Kabalah-Amitai et al., Science 340, 454-457 (2013).

26. E. Mugnaioli et al., Angew. Chem. Int. Ed. 51, 7041-7045 (2012)

27. G. Pawley, J. Appl. Cryst. 14, 357-361 (1981). 
28. M. M. J. Treacy, J. M. Newsam, M. W. Deem, Proc. R. Soc. London Ser. A 433, 499-520 (1991).

29. S. Bette, R. E. Dinnebier, D. Freyer, J. Appl. Cryst. 48 , 1706-1718 (2015)

30. A. Kudielka et al., J. Mater. Chem. C Mater. Opt. Electron. Devices 5, 2899-2909 (2017)

\section{ACKNOWLEDGMENTS}

Funding: Z.Z. was supported by China Scholarship Council (CSC) P.U.P.A.G. acknowledges DOE grant DE-FG02-07ER15899 and NSF grant DMR-1603192. The XANES-PEEM spectra were acquired at the Advanced Light Source, supported by DOE grant DE-AC0205CH11231. Author contributions: Z.Z., W.J.E.M.H., and P.F conceived of and planned the experiments. Z.Z. synthesized all samples; performed and analyzed the titration experiments; and performed laboratory XRD, IR, and Raman spectroscopy, as well as ICP-OES, TGA/DSC, and SEM measurements. S.W. helped to analyze the IR data. Y.P. and M.A.H. performed XANES spectroscopy at calcium K-edge and Y.P., M.A.H., and Z.Z. analyzed the data. Z.Z., C.-y.S., and P.U.P.A.G. performed XANES spectroscopy at oxygen K-edge and calcium L-edge and analyzed the data. L.B., A.C.S.J., Y.P., and W.J.E.M.H. performed the x-ray total scattering measurements. Z.Z. and L.B. analyzed the x-ray total scattering data. P.W. performed TEM measurements and J.M. acquired initial three-dimensional electron diffraction data. G.M. and U.K. performed ADT measurements and analyzed the ADT data. S.B. and R.D. created the microstructural model. I.P. and B.P. collected HRXRPD pattern. Z.Z., W.J.E.M.H., I.P., B.P., A.C.S.J., L.B., S.B., R.D., U.K., E.Z., and P.F. analyzed and interpreted the HRXRPD data. Z.Z., W.J.E.M.H., and E.Z. led the drafting of the manuscript and compiled the figures. All authors discussed the results and provided feedback on the manuscript. Competing interests: Authors declare no competing interests. Data and materials availability: All data needed to evaluate the conclusions in the paper are present in the paper or the supplementary materials.

\section{SUPPLEMENTARY MATERIALS}

www.sciencemag.org/content/363/6425/396/suppl/DC1 Materials and Methods

Figs. S1 to S12

Tables S1 to S6

References (31-43)

Data S1

6 August 2018; accepted 3 December 2018

10.1126/science.aav0210 


\section{Science}

\section{A hydrated crystalline calcium carbonate phase: Calcium carbonate hemihydrate}

Zhaoyong Zou, Wouter J. E. M. Habraken, Galina Matveeva, Anders C. S. Jensen, Luca Bertinetti, Matthew A. Hood, Chang-yu Sun, Pupa U. P. A. Gilbert, Iryna Polishchuk, Boaz Pokroy, Julia Mahamid, Yael Politi, Steve Weiner, Peter Werner, Sebastian Bette, Robert Dinnebier, Ute Kolb, Emil Zolotoyabko and Peter Fratzl

Science 363 (6425), 396-400.

DOI: $10.1126 /$ science.aav0210

\section{Hydrous $\mathrm{CaCO}_{3}$ gets a new structure}

Calcium carbonate $\left(\mathrm{CaCO}_{3}\right)$ forms important minerals on Earth and is a model system for understanding crystal nucleation. Three different structures of $\mathrm{CaCO}_{3}$ are known, along with two structures that are hydrated. Zou et al. found a third hydrated $\mathrm{CaCO}_{3}$ structure formed from amorphous $\mathrm{CaCO}_{3}$ in the presence of magnesium ions. The discovery illustrates the importance of amorphous precursors for producing new materials.

Science, this issue p. 396

ARTICLE TOOLS

SUPPLEMENTARY MATERIALS

REFERENCES

PERMISSIONS http://science.sciencemag.org/content/363/6425/396

http://science.sciencemag.org/content/suppl/2019/01/23/363.6425.396.DC1

This article cites 43 articles, 10 of which you can access for free http://science.sciencemag.org/content/363/6425/396\#BIBL

http://www.sciencemag.org/help/reprints-and-permissions

Use of this article is subject to the Terms of Service

Science (print ISSN 0036-8075; online ISSN 1095-9203) is published by the American Association for the Advancement of Science, 1200 New York Avenue NW, Washington, DC 20005. 2017 (C) The Authors, some rights reserved; exclusive licensee American Association for the Advancement of Science. No claim to original U.S. Government Works. The title Science is a registered trademark of AAAS. 